
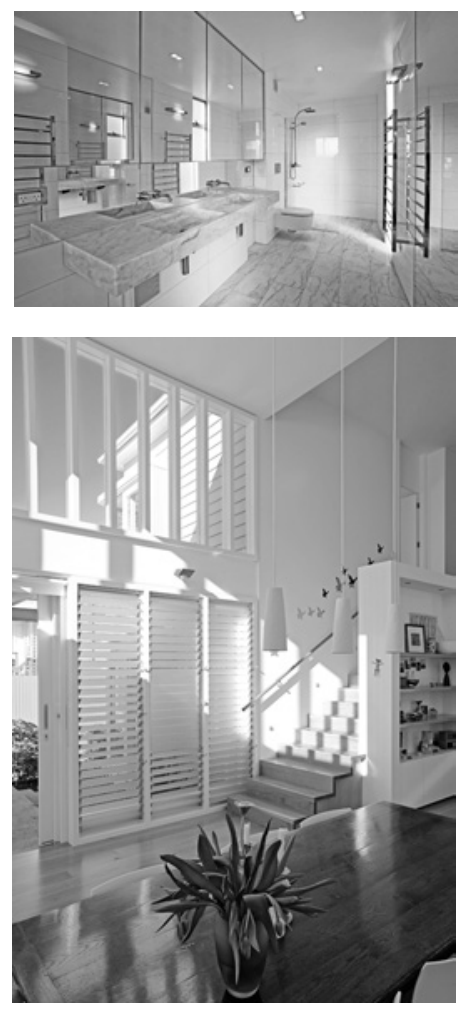

Top: Architect G. Tarrant, Photographer P. Reynolds. Bottom: Architect B. Hulena, Photographer T. Eyre (Home NZ October/November 2008).

1 Hilde Heynen discusses Le Corbusier's Law of Ripolin and the desire for 'inner cleanness' (2005: 20).

2 Jeremy Hansen, editor of Home NZ Magazine, suggests that a preference for illuminated interior images may also be due to an inability of print processes to render details in dark, shadowy images appropriately (pers. comm. 23.8.11).

3 Tanizaki (1886-1965) laments the eradication of shadow from the interior in Japanese architecture due to the influence of what he regards as a Western preoccupation with light.

4 'Māori' architecture is not separated here from that of the "Pacific region". While there is clearly a uniquely Māori architecture, which developed separately from the architecture of other, also diverse, Pacific cultures, for the purposes of this discussion of contained shadow and interior darkness, the similarities are important. While I cannot speak with authority about $\mathrm{Pacific}$ architecture, it seems important to me to look at architecture with a concern for Pacific space and its influence on contemporary New Zealand architecture. See publications by Mike Austin, Deirdre Brown, Tina EngelsSchwarzpaul, Rau Hoskins, Albert L. Refiti, Jeremy Treadwell, Sarah Treadwell, and Amanda Yates, among others.

\section{Interior Darkness / Contained Shadow}

\author{
Lynda Simmons
}

One reason for a tendency in New Zealand architecture to feature brightly lit interiors is perhaps an association of sunlight with health, cleanliness and wellbeing; ${ }^{1}$ another the perception of openness to the landscape as an authentic 'Kiwi' outdoors dwelling experience. This tendency certainly became an obsession of the New Zealand architectural media from the 1950s: professional photography increasingly produced images of light-filled spaces in step with the building industry's shift to larger glass panel sizes. As each decade brought advancements in technology, both in building and in print, images of interiors became ever brighter. ${ }^{2}$ As modernist ideas gained influence in New Zealand, a shadowy interior became, more and more, a sign of some sort of architectural failure, an inability to eradicate darkness.

My attention to shadow here is not to deny the beauty of the New Zealand sunlight, with its blue-based colour spectrum and strong contrasts, around which has been constructed a sense of national identity (Pound 2009: 95-96). Instead, it is to take notice that the beauty found in "the secrets of shadows" (Tanizaki 1988: 33) has been overlooked. Dark interiors, in combination with strongly illuminated planes, carry their own powerful aesthetic, and I want to argue here that this, too, is an important character of New Zealand architecture. Dark interiors here rely on the co-existence of strong Pacific light and the glare that occurs at the overlap. Jun'ichiro Tanizaki, a Japanese novelist, considers the predisposition towards an aesthetic which favours shadow and interior darkness in In Praise of Shadows. ${ }^{3} \mathrm{He}$ suggests that climate and available materials historically provided the reasons for deep, low eaves and recesses of shadow in Japanese buildings. But then, "our ancestors, forced to live in dark rooms, ... came to discover beauty in shadows, [and] ultimately to guide shadows towards beauty's ends" (1988: 31).

The term 'shadow' can apply to three separate conditions: the cast shadow, modulation or shade, and the contained shadow. I am particularly interested in the last condition here. The first type, the cast or projected shadow, is essentially two-dimensional in character and created by a light source, a castor object and a screen (Casati 2004: 1387). The second, shade, refers to the protective qualities offered through light modulation and has generally undefined, soft edges. The shade of a canopy, for instance, or the modulation of light across a form are spatially protective and occupy the realm between two-dimensional and three-dimensional form. Third, contained shadow requires three-dimensional boundaries and is three-dimensional itself.

Tanizaki's notion of the beauty of darkness is found in many aspects of Japanese interiors, and it relates to this third condition of contained shadow. An example of this aesthetic approach is the alcove, which is filled with blackness rather than flooded with light. Tanizaki recognises that, if the shadow were "to be banished from its corners, the alcove would in that instant revert to mere void" (1988: 34).

\section{Shadow in Pacific buildings}

New Zealand, like Japan, is located on the edge of the Pacific Rim, and there are similarities between the deep, contained shadows described by Tanizaki and those found in other Pacific interiors. There are numerous and complex layers of "Pacific Architecture"4 and the recently fashionable label "Pacific" can be 
misleading. For instance, it is increasingly applied to buildings characterised by nautical elements, lightness, membrane technologies and temporary materials. I propose, however, that the reverse is also true: Pacific buildings are not necessarily, or even primarily, tensile structures of lightness - they are also part of an architecture of shadow, characterised by the same heavy darkness found in Japan.

The bounded porch space of a Māori whare nui (meeting house) is at times filled with shadow, even when the roof line is surrounded by the glare of the contrasting New Zealand bright sky. This defined, three-dimensional shadow becomes a threshold moment between the expanse of the marae atea (open area in front of the whare nui) and the near-complete darkness of the whare's interior. As a transition space, the deep porch mediates between the space of debate (marae atea) and the space of peace (interior) (Brown 2009: 54). From the interior, the glare through the window and door openings is in stark contrast with the dark inside. In this inner realm, a world of formal richness, ritual ordering and material texture reveals itself only slowly on a bright summer's day, as the eye adjusts to the light conditions. Until then, the richness of the interior remains at the very edge of darkness, and the darkness itself assumes a sense of materiality. ${ }^{5}$ The glare, separating and connecting the inner realm and the illuminated plane beyond, is part of the aesthetic pleasure derived from the shadows set against the exterior brightness. ${ }^{6}$

In a Samoan faletele (council house), Tanizaki's heavy darkness hanging beneath the eaves is particularly palpable. Seen from inside, the contained shadow seems in fact lifted from the ground plane and suspended within the curved roof, which is pushed up from the paepae (raised platform) by the posts. As light slides in from the transparent edges, the heavy darkness appears to be lifted from the floor. The glare at the edges is powerful and further exaggerates the black depth held within the roof. Again, though, the eye adjusts and the complex texture of the inside surfaces is revealed. In both the faletele and wharenui, as well as many other building types of the Pacific region, to be inside is to experience deep shadow, contained and held above head height, and set against a rich textural interior. The contrast with the glaring Pacific sun is both a relief and a difficulty.

In New Zealand, there are some beautiful architectural examples which celebrate this condition of "interior darkness", despite the popular pursuit of cleanliness and purity through light. One notable example is John Scott's (1924-1992) Futuna Chapel in Karori, Wellington (1958-61).
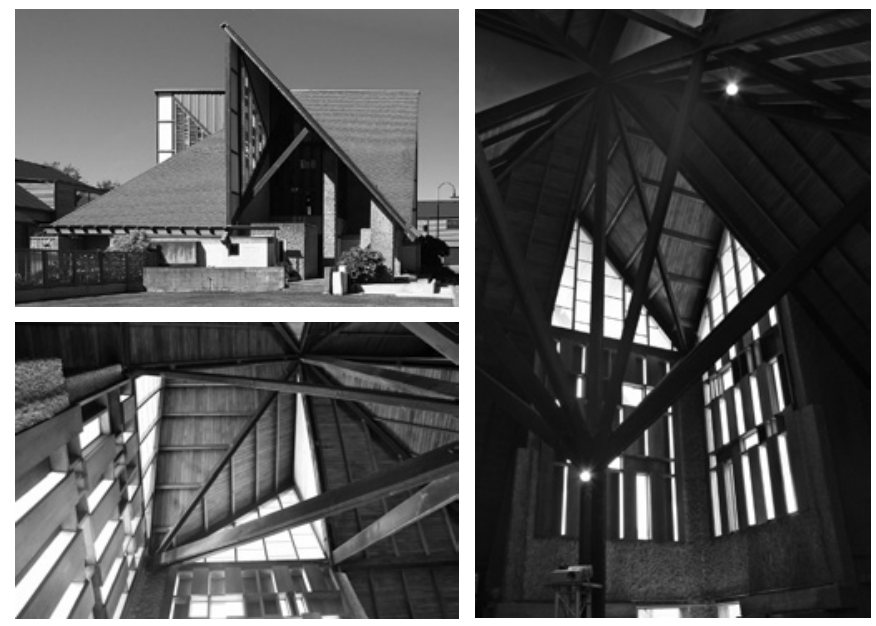

Futuna Chapel, Karori, Wellington. Designed by John Scott (1961) Exterior photo: Tony Wills, interior photos: L. Simmons
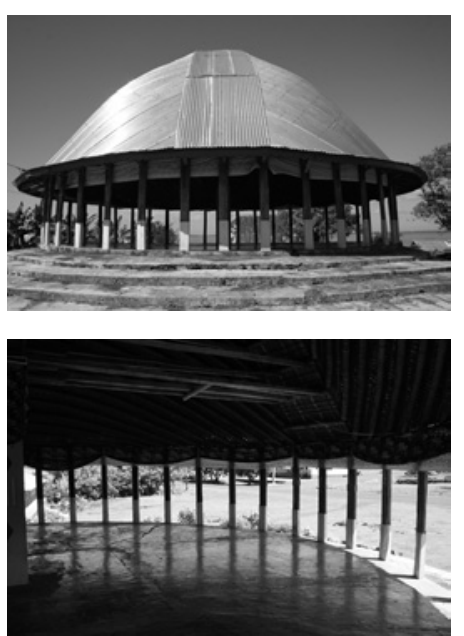

Faletele interiors and exterior, Salelologa, Savaii, Samoa Nuku-TeApiapi, Whakarewarewa

Photo: Auckland Museum (R. Neich)
5 Bachelard discusses the way shadow can take on a sense of materiality: "Water becomes heavier, darker, deeper; it becomes matter ... Then night becomes a substance as water is a substance." (Bachelard 1983: 20 \&53)

6 Aesthetic pleasure relates to concepts of prospect and refuge (see Hildebrand 1999). 
The building's complex and folding interior-exterior articulations appear to reverse the threshold between inside and out. Although based on a clear geometrical diagram, the roof form seems to turn inward and outward, creating a Moebius Strip-like confusion. And yet, the interior is strongly delineated: it is a dark, inward space, clearly defined with solid walls, which leave no doubt about the separation of the interior from the exterior and from the natural light. From the exterior, the deeply triangulated eaves hold shadow in a defined volume - this contained shadow appears to be part of the roof form itself. The shadow takes on a condition of materiality, with a sense of density and solidity usually ascribed to materials such as oil, and some metals and granites. The contained shadow continues inward, to the core of the interior. Many critics have commented on similarities between the chapel and a wharenui, but the reference points are usually the large central pole and small-scale entrance; the characteristic of a contained interior darkness is not usually discussed and analysed.

Light is allowed inside only through carefully composed openings. The building behaves almost as an internal sun-dial, tracing the sun as it slices the undulating interior spaces. Much has been written about this light and its spiritual nature, ${ }^{7}$ but I have found nothing yet about the interior's contained shadow. For me, the shadow conveys a familiar and welcoming sense of personal, yet shared space. Sitting under the low part of the hip roof near the solid enclosing wall on my first visit to the Futuna Chapel in 2011, and experiencing the soaring vertical space towards the glare, I was reminded of being in the home of my childhood, designed by my father, Neil Simmons, in 1964. I saw links, in era and design approach, between the chapel and the Simmons house, a connection I had never made when looking at the published images of the chapel.

In the Simmons house, this shadow is defined by the reveals and projections to the northern corner, and continues into the interior, culminating in the living room corner. Eschewing contemporary trends towards interior brightness, this home was intentionally designed with darkness at its core. The living room is located under the lowest corner of the hip roof and performs as the literal and metaphorical anchor to the home. There are no windows at all in the living room (apart from the strip glass detail at the roof/wall junction), yet there is no sense of claustrophobia; this area is connected to the shared space and to the brightness of the glazed wall beyond. Solid walls without windows (like in the Futuna Chapel) are a point of difference from the majority of New Zealand living rooms, which are generally oriented towards 'the view'. The gaze is inward and personal. ${ }^{8}$ The kitchen bench unit floats between the living room corner and the bright glazed wall, allowing the light to slide along the tiled floor. To someone sitting in the living room, the ceiling angles upwards and outwards towards the light, and a cave-like space is created. Protected and personal, it is nevertheless visually connected, past the free-floating 'fireplace', to the bright exterior which amplifies the glare, both uncomfortable and reassuring. The resulting aesthetic appeal is due to both conditions.

The success of design with darkness at its core seems to be reliant on two accompanying conditions: first, free space in the plan and, second, the relationship to the glare of an illuminated plane. Thus, the brightly lit ground surface of the marae atea is adjacent to the dark interior; in the faletele, the illuminated plane extends horizontally under the contained shadow of the roof; and, finally, the vertical planes of light in the Futuna Chapel are set above and into the dark, solid interior. In the Simmons house, illuminated plane and shadow are juxtaposed in both the horizontal and the vertical planes - the ground surface of the yard, and the glass-walled corner to the north of the house. Equally important is the free space 


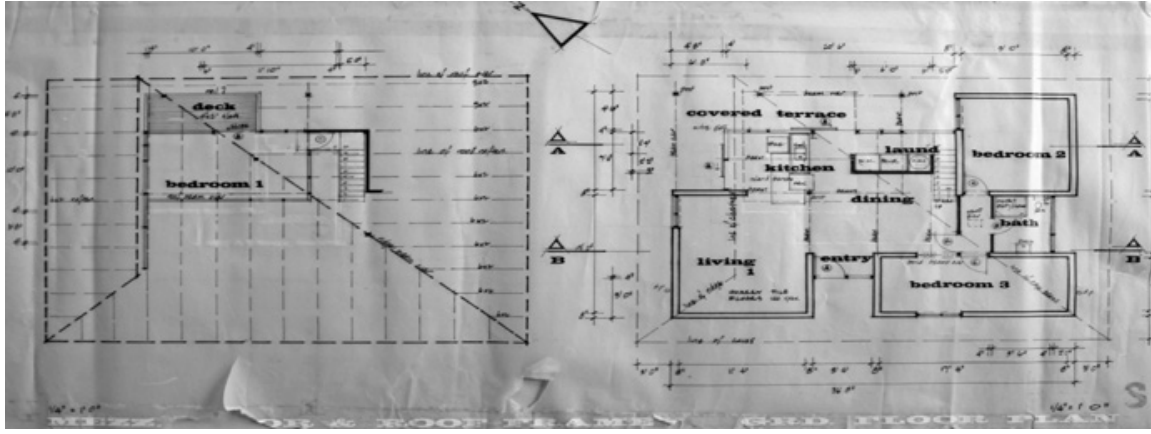

Simmons House Floor Plans - Ground Floor and Mezzanine. Drawing by Neil Simmons 1968.

of the plan, as it seems that the intrusion of obstacles may destroy the beauty of interior darkness. This absence of objects and the clear centre-space is typical of architecture in the Pacific region, which is often described by Western observers as 'empty'. In the Simmons house, three corner-forms are pulled apart to create a cleared, central space, which has no function or object to define it, into which the mind can project, and through which bodies can move. Shadow, with its ability to become 'material', provides a quality of fullness to such interior spaces - they are therefore far from empty. ${ }^{9}$

\section{Modernism and an invisible tradition}

Modernist-conditioned fears of dark interiors are foreign to this home, in fact the shadowy interior is welcome and provides a sense of personal comfort. In my own experience, this personal comfort extends not to the individual, but to a shared space. The separation from public life here does not create privacy but nurtures the family group. This is in contrast to Walter Benjamin's, Sigfried Giedion's and others' calls to abandon "... dwelling as seclusion and security ..." in favour of transparency and egalitarianism (Heynen \& Baydar 2005: 18). It is tempting to align the brightening of Western interiors over the last century, and the presentation of this brightness in publications, with the gradual 'making public' of domestic life. Not only do the objects displayed become less and less personal but so, too, does the spatial character of the interior itself. Sunlight chases all shadow away from the interior, along with possible fears of ill-health or immorality associated with it. The result is a lack of those intensely personal spaces typical of both individual and shared family life.

Yet, the use of building forms with deep, shadowed reveals and dark interiors does contribute to a particular character of New Zealand architecture, one with a sense of interior intensity. Recent work by Michael O'Sullivan draws upon the beauty of shadow when, in the design of his family home in Mangere, he sets up what Peter Wood describes as a "classic prospect/retreat scenario" (2009: 71). In his design for a house in the Waitakere Ranges, which has recently been awarded the title of Home of the Year 2011 (Hansen 2011: 64-76), O'Sullivan again employs dark interior spaces. This has not been discussed in any publication to date. ${ }^{10}$ The very nonpublic nature of interior darkness has possibly created a self-imposed exclusion from mainstream magazines, and thereby from the public eye. In my experience, it is not usually productive to discuss interior darkness with clients, who also tend to favour the idea that more light will produce a better space. There seems to be a collusion of sorts, between the publishers of architectural images and architects themselves. ${ }^{11}$ Nevertheless, further investigation may yet reveal that the beauty of shadows has not been banished from New Zealand architecture but only from the published images and discussions of architecture.
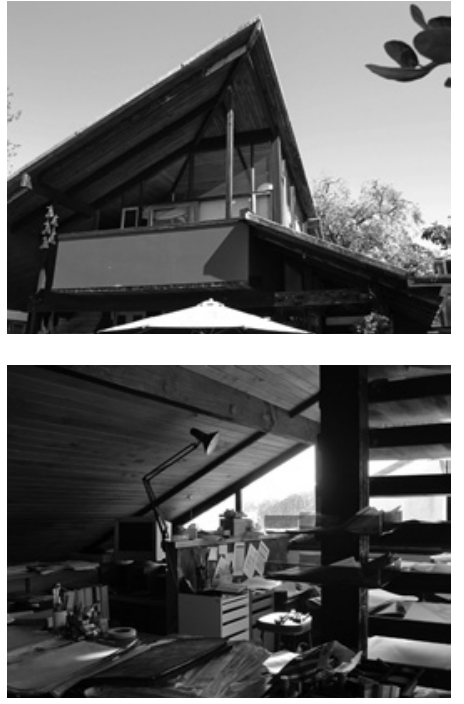

Simmons House interior studio and First Level covered deck, Eastern Beach, Auckland. Designed by Neil Simmons (1964) Photos by L.Simmons

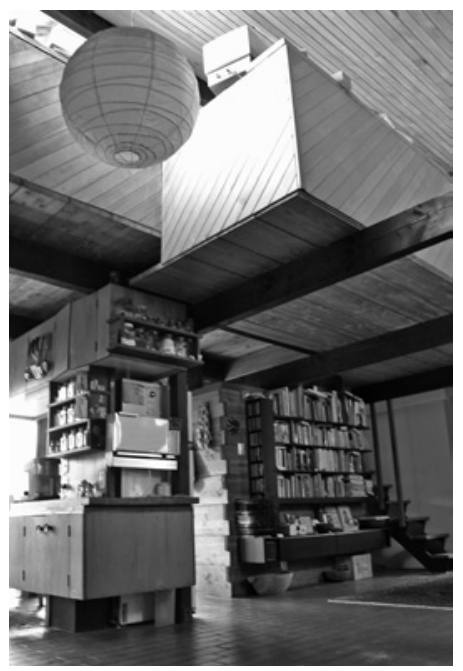

Simmons House interior, Ground Floor. Eastern Beach, Auckland. Designed by Neil Simmons (1964). Photos by L.Simmons

9 About space as empty and space arising from ritual, see Engels-Schwarzpaul on p.17 in this issue.

10 Despite the shadowy interiors being shown in print, TV and video footage (Home NZ, Campbell TV3, 3.8.2011, Home NZ show reel), the subject of darkness or shadow is not directly addressed. The architect, though, does refer to the "intensity of the interior"in an interview on the show reel.

11 See John Walsh on p.111 of this issue. 


\section{References}

Bachelard, G. (1983). Water and Dreams: An essay on the imagination of matter (E. R. Farrell, Trans.). Dallas: Pegasus.

Brown, D. (2009). Māori Architecture: From fale to wharenui and beyond. Auckland: Penguin (NZ).

Brown, D. (2005). John Scott: Inventing an idiom. Heritage New Zealand, 98, 8-13.

Campbell Live, TV3, 3 News. (2011). A peek inside the 2011 Home of the Year. Retrieved 20 August, 2011, from http://www.3news.co.nz/A-peek-inside-the-2011-Home-of-the-Year/tabid/817/ articleID/220935/Default.aspx

Casati, R. (2004). The Shadow Knows: A primer on the informational structure of cast shadows. Perception 33, 2-4.

Dickson, J. (1982). The Mastery of Space, Part One: space, shape, movement and their social implications. Study Paper 66. Auckland: The University of Auckland School of Architecture. Unpublished paper.

Dickson, J. (1982). The Mastery of Space, Part Two: material - texture and colour. Study Paper 67. Auckland: The University of Auckland School of Architecture. Unpublished paper.

Dickson, J. (1982). The Mastery of Space, Part Three: Environment - light, sound, heat, water, taste \& smell. Study Paper 68. Auckland: The University of Auckland School of Architecture. Unpublished paper.

Engels-Schwarzpaul, A.-Chr. (2011). Restless Containers. Interstices, 12, 11-22.

Heynen, H. (2005). Modernity and Domesticity: Tensions and contradictions. In H. Heynen \& G.Baydar (Eds.), Negotiating Domesticity. Spatial Productions of Gender in Modern Architecture. (pp 1-29). Abingdon and New York: Routledge.

Hansen, J. (2011). Between Sea and Sky. Home NZ, Aug/Sept, 64-76.

Hildebrand, G. (1999). Origins of Architectural Pleasure. Berkeley and Los Angeles (Ca.): University of California Press.

Home NZ (2011). Home of the Year [showreel]. Retrieved 20 August, 2011, from http:// homenewzealand.blogspot.com/

Pound, F. (2009). The Invention of NZ. Art and National Identity 1930-1970. Auckland: Auckland University Press.

Rennie, J. (2010). Silenced by Coloured Light. Auckland: Unitec. First International Conference 2010 Proceedings.

Tanizaki, J. (1991). In Praise of Shadows (T. J. Harper \& E. G. Seidensticker, Trans.). London: Jonathan Cape.

Walden, R. (1987). The Voices of Silence: New Zealand's Chapel of Futuna. Wellington: Victoria University Press.

Walsh, J. (2011). Just Looking. Interstices, 12, 111-113.

Wood, P. (2009). Doing it Yourself. Home NZ, Aug/Sept, 62-71. 